\title{
Effect of alpha-lipoic acid on arterial stiffness parameters in type 2 diabetes mellitus patients with cardiac autonomic neuropathy
}

\author{
Victoria A. Serhiyenko ${ }^{1}$, Ludmila M. Serhiyenko ${ }^{1}$, Volodymyr B. Sehin ${ }^{2}$, Alexandr A. Serhiyenko ${ }^{1}$ \\ ${ }^{1}$ Danylo Halytsky Lviv National Medical University, Lviv, Ukraine; ${ }^{2}$ Lviv Regional State Clinical Treatment \\ Endocrinological Center, Lviv, Ukraine \\ E-mail: serhiyenkov@gmail.com
}

\begin{abstract}
Objective. Significantly underdiagnosed, diabetes-associated cardiac autonomic neuropathy (CAN) causes a wide range of cardiac disorders that may cause life-threatening outcomes. This study investigated the effects of alpha-lipoic acid (ALA) on arterial stiffness and insulin resistance (IR) parameters in type 2 diabetes mellitus (T2D) patients and definite CAN.

Methods. A total of 36 patients with T2D and a definite stage of CAN were recruited. This investigation was carried out on two separate arms: traditional hypoglycemic therapy ( $\mathrm{n}=18$, control) and ALA ( $\mathrm{n}=18) 600 \mathrm{mg}$ in film-coated tablets/q.d. in addition to traditional hypoglycemic therapy. The duration of the study was three months.

Results. In subjects with T2D and definite stage of CAN, treatment with ALA resulted in a significant decrease of glucose, immunoreactive insulin concentration, and Homeostasis Model Assessment (HOMA)-IR (HOMA-IR) parameters; pulse wave velocity (PWV), aorta augmentation index (AIxao) during the active period of the day and decrease of PWV, AIxao, and brachial augmentation index during the passive period of the day compared with the results, obtained in the control group. Therefore, the administration of ALA to patients with T2D for three months promotes the improvement of glucose metabolism and arterial stiffness parameters.

Conclusions. In patients with T2D and definite stage of CAN treatment with ALA improved HOMA-IR and arterial stiffness parameters. These findings can be of clinical significance for the complex treatment of diabetes-associated CAN.
\end{abstract}

Key words: cardiac autonomic neuropathy, type 2 diabetes mellitus, arterial stiffness, alphalipoic acid

Coronary artery disease (CAD) due to early coronary atherosclerosis is often diagnosed among type 2 diabetes (T2D) patients. The term "diabetic heart" is associated with early affection of coronary arteries, development and progression of arterial atherosclerosis, diabetic cardiac autonomic neuropathy (CAN) and diabetic cardiomyopathy among middle age and elderly patients (Balcioglu and Muderrisoglu 2015; Serhiyenko and Serhiyenko 2015; Verrotti et al. 2014; Vinik et al. 2013).
According to the CAN Subcommittee of the Toronto Consensus Panel on Diabetic Neuropathy (Spallone et al. 2011) and the American Diabetes Association (American Diabetes Association 2017), CAN is defined as the impairment of cardiovascular autonomic control among persons with diabetes mellitus (DM) following the exception of other reasons. Hyperglycemia has a significant impact on the advancement of autonomic neural dysfunction and can result in CAN (Pop-Busui et al. 2017).

Corresponding author: PhD, MD, Professor Victoria A. Serhiyenko, Department of Endocrinology, Danylo Halytsky Lviv 
Diabetic CAN is one of the main reasons for heart arrhythmias and an independent risk factor for sudden cardiac death (Pop-Busui et al. 2017; Ziegler et al. 2014). This condition is characterized by the impairment of the autonomic nervous system (ANS), namely by lesion of nerve fibers in the sympathetic and parasympathetic divisions of the ANS. CAN is mostly a late-diagnosed complication that could lead to the development of severe orthostatic hypotension $(\mathrm{OH})$, decreased tolerance to the physical loadings, cardiac arrhythmias, ischemia of coronary vessels, "silent" myocardial infarction, and sudden death syndrome (Dimitropoulos et al. 2014; Spallone et al. 2011; Tesfaye et al. 2010). Especially at the early stages, this complication can be subclinical and thus as the disease progresses, it manifests clinically (Vinik et al. 2013, 2018).

Arteriosclerosis is one of the key reasons for the thickening, hardening and loss of the arteries' wall elasticity. Structural components of the arterial wall primarily determine arterial stiffening, depends on the balance and distribution between extracellular proteins along the arterial wall, vascular smooth muscle tone and transmural distending pressure (Townsend et al. 2015).

Arterial stiffness is associated with cardiovascular mortality and morbidity and is increased with aging, several diseases, namely obesity, hypertension (HT), T2D. Increased arterial stiffness associated with diabetes and metabolic syndrome (MetS) may, in part, explain the increased risk of the development of cardiovascular disease among patients with these diseases (Stehouwer et al. 2008). Violations in heart rate variability (HRV) are an early sign of CAN development. It was proven that low HRV is associated with an increased mortality rate in persons with DM or ischemic heart disease (Huikuri and Makikallio 2001; Maser et al. 2003; Sessa et al. 2018). HRV was considered as a sensitive indicator of baroreflex control, especially vagal control. Accordingly, increased arterial stiffness may affect baroreceptor function and, thereby, HRV (Lal et al. 2017; La Rovere et al. 2001; Sleight et al. 1995). Pulse wave velocity (PWV) was considered as the gold standard for arterial stiffness measurement, which can be non-invasively measured using certain devices by evaluating waveforms in the carotid and femoral or radial artery (Colussi et al. 2017; Koumaras et al. 2013; Mansour et al. 2013). The Deutsche Kardiale Autonome-Neurophathie (DEKAN) study demonstrated that a daily oral dose of $800 \mathrm{mg}$ alpha-lipoic acid (ALA), a freeradical scavenger, may have positive clinical effects in the treatment of persons with diabetic CAN (Ziegler et al. 1997). However, trials regarding ALA features in diabetic patients without diagnosed CAD are scarce, and the results are inconclusive (Lee et al. 2017).

The effects of ALA on endothelial function and oxidative stress (OS) markers were age-dependent. In contrast, a review of many clinical studies using chronic antioxidant therapy could not demonstrate the benefits on cardiovascular diseases (Gomes and Negrato 2014; Lee et al. 2017).

This study was conducted to determine if ALA prescription affects the arterial stiffness parameters, insulin resistance (IR), and glycemic control in patients with T2D and definite stage of CAN.

\section{Materials and methods}

Participants and study design. Definite CAN was diagnosed in 36 patients, aged between 50-59 years, with confirmed T2D. The duration of T2D was between 1-6 years and glycated hemoglobin Alc (HbAlc) level were $6.98 \pm 0.15 \%$. The baseline clinical characteristics of the patients are presented in Table 1.

A proper diet and exercise program were prescribed to all patients. All of them used antidiabetic drugs, namely metformin alone was used by $69.4 \%$ and combined with sulfonylureas was prescribed to $30.6 \%$. $80.6 \%$ of persons suffered from treatmentcontrolled HT, which was controlled by prescription

Table 1

Clinical characteristics of patients

\begin{tabular}{lcc}
\hline \multirow{2}{*}{ Parameters } & \multicolumn{2}{c}{$\begin{array}{c}\text { Patients with T2D and definite } \\
\text { stage of CAN (n=36) }\end{array}$} \\
\cline { 2 - 3 } & Control (n=18) & ALA (n=18) \\
\hline Age (years) & $55.16 \pm 0.91$ & $54.0 \pm 0.94$ \\
Gender & & \\
\hline \multicolumn{1}{c}{ Male (\%) } & $10 / 55.6 \%$ & $11 / 61.1 \%$ \\
\hline Female (\%) & $8 / 44.4 \%$ & $7 / 38.9 \%$ \\
\hline Diabetes duration (years) & $3.7 \pm 0.44$ & $3.5 \pm 0.42$ \\
BMI (kg/m $\left.{ }^{2}\right)$ & $27.19 \pm 0.41$ & $26.19 \pm 0.39$ \\
Medications & & \\
\hline \multicolumn{1}{|c|}{ ACE inhibitors/ ARBs (\%) } & $14 / 77.8 \%$ & $14 / 77.8 \%$ \\
\hline $\begin{array}{l}\text { B-blockers (\%) } \\
\text { Metformin (\%) }\end{array}$ & $4 / 22.2 \%$ & $3 / 16.7 \%$ \\
\hline $\begin{array}{l}\text { Combined hypoglycemic } \\
\text { therapy (\%) }\end{array}$ & $13 / 72.2 \%$ & $12 / 66.7 \%$ \\
\hline Hypertension (\%) & $5 / 27.8 \%$ & $6 / 33.3 \%$ \\
\hline Abbrevitions: ACE & $14 / 77.8 \%$ & $15 / 83.3 \%$ \\
\hline
\end{tabular}

Abbreviations: ACE - angiotensin-converting enzyme; ARBs - angiotensin II receptor blockers; BMI - body mass index; CAN - cardiac autonomic neuropathy; T2D - type 2 diabetes mellitus. 
of angiotensin II receptor blockers or angiotensinconverting-enzyme inhibitors alone or in combination with $\beta$-adrenergic receptor blockers. Antihypertensive and antidiabetic treatment remained unchanged for six months before initiating the study and during the whole investigation period. At baseline, both groups were similar in sex, age, body mass index (BMI), and DM duration, concomitant therapy, which made them as homogeneous as possible. All involved patients were allocated into two groups: the control group included 18 patients, the ALA group treatment group $(\mathrm{n}=18)$.

Persons included in the study were examined and treated in the Department of Endocrinology of the Danylo Halytsky Lviv National Medical University, based in an Endocrinological out-patient department of Lviv Regional State Clinical Treatment and Diagnostical Endocrinological Center. On the basis of these institutions, patients were examined and treated. The research was conducted according to the Declaration of Helsinki (2004) and the Ethics Committee of the Danylo Halytsky Lviv National Medical University approved the study before its initiation (protocol №1 from 01 Jan 2016). All study participants provided written informed consent before their inclusion in the study.

All patients received standard antidiabetic treatment that included an appropriate diet, physical activity and oral antihyperglycemic drugs. Treatment of the control group remained unchanged during the study. Besides, participants from the ALA group were administered thioctic acid $600 \mathrm{mg}$ in film-coated tablets/q.d. for three months.

Eligibility criteria were specified as follows: women and men aged between 50-60 years old; T2D with optimal or suboptimal glycemic control; T2D persons with confirmed definite CAN; BMI between $20-30 \mathrm{~kg} / \mathrm{m}^{2}$; ability to maintain a healthy lifestyle.

Study exclusion criteria were specified as follows: poorly controlled DM, ketosis, peripheral vascular diseases, ischemic form, distal neuropathy resulted from other causes than diabetes (pharmacological agents, neurological disease, chronic alcoholism), tumors, hypothyroidism, history of acute pancreatitis, the affected activity of lipoprotein lipase and/or dyslipidemia (DLP) type III, type 1 DM, hypersensitivity to ALA. Treatment with anticonvulsants, antidepressants, capsaicin, opiates, cytostatic and neuroleptic agents, gamma-linoleic acid, B group vitamins, aldose reductase inhibitors, isotretinoin (Accutane), antioxidants (including ALA) for six months before the enrollment into the study. Patients with clinical diagnosis of stroke, transient ischemic cere- bral attack, chronic heart failure (HF) with reduced ejection fraction (New York Heart Association class II-IV); acute coronary syndrome, or hospitalization for worsening HF; chronic obstructive lungs diseases; acute renal failure, chronic kidney disease with a decrease in glomerular filtration rate less than $60 \mathrm{~mL} / \mathrm{min} / 1.73 \mathrm{~m}^{2}$; hepatic insufficiency classified as Child-Pugh B-C were also excluded from the study.

The study was conducted for 2 years. All patients were on the stable antidiabetic and antihypertensive treatment regime and did not take ALA for 6 months before the enrollment. According to the study design, ALA was prescribed to patients from the treatment group after CAN diagnosis. The treatment in the control group remained unchanged. The duration of the treatment period with ALA was three months. According to the study purpose, IR, artery stiffness, and glycemic control parameters were evaluated initially and after the treatment.

Methods. Cardiovascular autonomic reflex tests (CART's) are the "gold" standard clinical tests for CAN. According to the CAN Subcommittee in the Toronto Diabetic Neuropathy Consensus Panel, only one abnormal CART result (among the seven tests (five CART's, HRV frequency, and time-domain tests) is sufficient for CAN diagnosis, two or three abnormal tests indicate definite CAN and development of $\mathrm{OH}$ indicate severe CAN (Ewing et al. 1985; Spallone et al. 2011).

Five CART's, time- and frequency-domain HRV tests were used to screen for CAN. According to the obtained results, the severity of CAN was determined. Each of the five tests was assigned a score of " 0 " for physiological value, " 0.5 " for borderline value, and " 1 " for pathological value (Ewing et al. 1985; Spallone et al. 2011). The scores were summed up and the median score for studied patients was $2.7 \pm 0.27$.

The glucose concentration was determined by the glucose oxidase method; the level of HbAlc was measured using D-10 analyzer and BIO-RAD reagents (USA) by the highly sensitive method of ionexchange liquid chromatography. Commercial kits from immunogen insulin immunoradiometric assay reagents (Czech Republic) were used to determine immunoreactive insulin (IRI). Homeostasis Model Assessment (HOMA)-IR (HOMA-IR) was calculated according to the formula: fasting IRI $(\mathrm{mcIU} / \mathrm{ml}) \times$ fasting glucose (mmol/L)/22.5 (Matthews et al. 1985).

Twelve-channel electrocardiograph "UCARD200" (UTAS, Ukraine) was used to perform electrocardiography (ECG) and Holter-ECG [ECG "The EC-3H" (Labtech, Hungary)] - to measure time- and frequency domain HRV parameters. TensioMed ${ }^{\mathrm{m}}$ 
Arteriograph [monitor "ABPM-04" ("Meditech", Hungary)] (TensioClinicTensioMed ${ }^{\mathrm{m}}$ ) was used to measure artery stiffness parameters during the day and night subperiods, namely: PWV, aorta augmentation index (AIxao) and brachial augmentation index (AIxbr). The optimal values: $\mathrm{PWV}<7 \mathrm{~m} / \mathrm{s}$, AIxbr $>-30 \%$; normal values: $7 \mathrm{~m} / \mathrm{s}<\mathrm{PWV}<10 \mathrm{~m} / \mathrm{s}$, $-30 \%<$ AIxbr $<-10 \%$; elevated values: $9.8 \mathrm{~m} / \mathrm{s}<\mathrm{PWV}$ $<12 \mathrm{~m} / \mathrm{s},-10 \%<$ AIxbr $<9.8 \%$; pathological values: $\mathrm{PWV}>12 \mathrm{~m} / \mathrm{s}$, AIxbr $>10 \%$ (TensioClinicTensioMed ${ }^{\mathrm{mm}}$; Townsend et al. 2015).

Statistical analysis. The normality of the presented data was checked using the Shapiro-Wilk test, and all the studied variables had a normal distribution. Absolute values were compared with the calculation of mean values, errors of means using the Student's t-test. Data are presented as mean \pm standard error of the mean $[\mathrm{D} \%$, mean \pm standard error of the mean $(\mathrm{SEM})]$. Statistical significance was set at $\mathrm{p}<0.05$. All tests were performed using the ANOVA (MicroCal Origin v. 8.0) software.

\section{Results}

The level of HbAlc in patients with T2D and definite stage of CAN did not change significantly after treatment ( $p>0.05$ ). Changes in glucose, IRI concentrations and HOMA-IR parameters in patients with T2D and definite stage of CAN after 3-months of ALA therapy are given in Table 2 .

The obtained results suggest that ALA prescription to patients with T2D and definite CAN contributes to a statistically significant reduction in preprandial glycemia $(\mathrm{p}<0.05)$; IRI levels $(\mathrm{p}<0.01)$ and HOMA-IR parameters $(\mathrm{p}<0.05)$. Investigated parameters did not change significantly in the control group (Table 2).

Changes of the arterial stiffness parameters during the day's active period in patients with T2D and definite stage of CAN after 3-months of ALA therapy are given in Table 3.

Changes of the arterial stiffness parameters during the day's passive period in patients with T2D and

Table 2

Changes of the glucose, IRI concentrations and HOMA-IR parameters in patients with T2D and definite stage of CAN after 3-months of ALA therapy

\begin{tabular}{lccccc}
\hline \multirow{2}{*}{ Parameters } & \multicolumn{5}{c}{ Patients with T2D and definite stage of CAN $(\mathbf{n}=36)$} \\
\cline { 2 - 6 } & Groups & Before treatment & After treatment & \% Change & p-value \\
\hline Glucose $(\mathrm{mmol} / \mathrm{L})$ & Control $(\mathrm{n}=18)$ & $7.0 \pm 0.24$ & $7.05 \pm 0.28$ & $+1.03 \pm 2.68$ & $>0.05$ \\
& ALA $(\mathrm{n}=18)$ & $6.68 \pm 0.22$ & $6.01 \pm 0.24$ & $-8.8 \pm 4.46$ & $<0.05$ \\
IRI $(\mathrm{mcIU} / \mathrm{mL})$ & Control $(\mathrm{n}=18)$ & $27.29 \pm 1.82$ & $26.14 \pm 1.94$ & $-4.5 \pm 2.21$ & $>0.05$ \\
& ALA $(\mathrm{n}=18)$ & $26.62 \pm 1.31$ & $22.17 \pm 0.97$ & $-15.9 \pm 1.6$ & $<0.01$ \\
HOMA-IR & Control $(\mathrm{n}=18)$ & $8.8 \pm 0.85$ & $8.39 \pm 0.79$ & $-4.47 \pm 2.4$ & $>0.05$ \\
& ALA $(\mathrm{n}=18)$ & $7.9 \pm 0.55$ & $6.04 \pm 0.48$ & $-23.3 \pm 3.94$ & $<0.05$ \\
\hline
\end{tabular}

Abbreviations: ALA - alpha-lipoic acid; CAN - cardiac autonomic neuropathy; HOMA-IR - Homeostasis Model Assessment of insulin resistance; IRI - immunoreactive insulin; SEM - standard error of the mean; T2D - type 2 diabetes mellitus. The results are presented as absolute values and as $\%$ change from baseline $(\Delta \%$, mean \pm SEM).

Table 3

Changes of the arterial stiffness parameters during the day's active period in patients with T2D and definite stage of CAN after 3-months of ALA therapy

\begin{tabular}{lccccc}
\hline \multirow{2}{*}{ Parameters } & \multicolumn{5}{c}{ Patients with T2D and definite stage of CAN $(\mathbf{n}=\mathbf{3 6})$} \\
\cline { 2 - 6 } & Groups & Before treatment & After treatment & \% Change & p-value \\
\hline AIxao (\%) & Control $(\mathrm{n}=18)$ & $30.3 \pm 1.75$ & $28.6 \pm 1.58$ & $-3.8 \pm 4.22$ & $>0.05$ \\
& ALA $(\mathrm{n}=18)$ & $29.8 \pm 1.54$ & $24.7 \pm 1.17$ & $-15.3 \pm 3.66$ & $<0.05$ \\
AIxbr (\%) & Control $(\mathrm{n}=18)$ & $-12.4 \pm 3.18$ & $-12.9 \pm 2.79$ & $-15.2 \pm 11.8$ & $>0.05$ \\
& ALA $(\mathrm{n}=18)$ & $-12.6 \pm 2.49$ & $-16.5 \pm 2.37$ & $-30.3 \pm 14.21$ & $>0.05$ \\
\hline PWV (m/s) & Control $(\mathrm{n}=18)$ & $10.1 \pm 0.38$ & $9.6 \pm 0.38$ & $-4.6 \pm 2.31$ & $>0.05$ \\
& ALA $(\mathrm{n}=18)$ & $10.1 \pm 0.4$ & $8.9 \pm 0.34$ & $-10.7 \pm 1.97$ & $<0.05$ \\
\hline
\end{tabular}

Abbreviations: AIxao - aorta augmentation index; AIxbr - brachial augmentation index; ALA - alpha-lipoic acid; CAN - cardiac autonomic neuropathy; PWV - pulse wave velocity; SEM - standard error of the mean; T2D - type 2 diabetes mellitus. The results are presented as absolute values and as $\%$ change from baseline $(\Delta \%$, mean \pm SEM $)$. 
definite stage of CAN after 3-months of ALA therapy are given in Table 4 .

As can be seen from the results presented in Table 3 and Table 4, ALA prescription to patients with T2D and definite CAN contributes to a statistically significant reduction in AIxao $(\mathrm{p}<0.05)$ and $\mathrm{PWV}(\mathrm{p}<0.05)$ during active period of day; $\mathrm{PWV}(\mathrm{p}<0.01)$, AIxao $(\mathrm{p}<0.05)$ and AIxbr $(\mathrm{p}<0.05)$ during the passive period of day. Investigated parameters did not change significantly in the control group ( $\mathrm{p}>0.05)$.

\section{Discussion}

Our study found out that treatment with ALA significantly reduced IR and arterial stiffness parameters. The action mechanisms are not completely clear; however, we hypothesize that these findings can be explained mainly by its antioxidant, anti-inflammatory effects, improvement of glucose uptake, and OS decrease. The major limitations of our study are the small number of patients and the short treatment duration. Larger studies with a follow-up period would be needed to demonstrate the pharmacological effect of ALA on investigated parameters more clearly.

The development of chronic complications of DM, including cardiovascular and nervous complications is a complex pathological process with a pivotal role of OS caused by reactive oxygen species (ROS) and reactive nitrogen species that is strongly associated with IR and DM (Frontoni et al. 2013; Serhiyenko and Serhiyenko 2018). OS is though-out as a main pathophysiological pathway of CAN development. Increased intracellular glucose level leads to activation of polyol pathway and generation of advanced glycation end-products (AGEs), resulting in the subsequent formation of ROS (Hosseini and Abdollahi 2013).

Impaired glucose and BP variability is associated with increased cardiac mass and endothelial dysfunction in patients with short-term diabetes and optimal metabolic control (Di Flaviani et al. 2011). The authors concluded that increased activation of OS might represent the mechanism, linking glucose variability, violated blood pressure patterns and left ventricular mass index. Our study involved patients with similar characteristics and our results suggest that prescription of ALA can improve arterial elasticity, possibly due to its antioxidant properties.

The development of IR often precedes the diagnosis of T2D. Results of some recent trials have suggested that increased arterial stiffness could be another feature of IR. At physiological concentrations, insulin has acute vasodilatory effects, but they are blunted in an insulin-resistant state, including T2D (Manrique et al. 2014; Yki-Jarvinen and Westerbacka 2007). The changes in arterial stiffness in the condition of chronic IR have also been examined. Inverse association between clamp-measured insulin sensitivity and arterial stiffness in the femoral and carotid arteries was found (Adeva-Andany et al. 2019; Emoto et al. 1998; Morioka et al. 2021; van Dijk et al. 2003). Importantly, these studies concluded that IR is associated with arterial stiffness changes even after adjustments for mean arterial pressure levels (Markus et al. 2019; Olsen et al. 2000; Sengstock et al. 2005). Particularly, the next trial, which has addressed the combined and individual effects of elevated glucose level and blood pressure (BP) on the arterial stiffness progression, has demonstrated that the estimated rate of arterial stiffness increase was higher in persons with both abnormalities than in those with either abnormality alone.

Table 4

Changes of the arterial stiffness parameters during the day's passive period in patients with T2D and definite stage of CAN after 3-months of ALA therapy

\begin{tabular}{lccccc}
\hline \multirow{2}{*}{ Parameters } & \multicolumn{5}{c}{ Patients with T2D and definite stage of CAN $(\mathbf{n}=\mathbf{3 6})$} \\
\cline { 2 - 6 } & Groups & Before treatment & After treatment & \% Change & p-value \\
\hline AIxao (\%) & Control $(\mathrm{n}=18)$ & $32.9 \pm 1.67$ & $30.7 \pm 1.21$ & $-4.7 \pm 3.52$ & $>0.05$ \\
& ALA $(\mathrm{n}=18)$ & $33.6 \pm 1.27$ & $28.6 \pm 1.37$ & $-14.3 \pm 2.29$ & $<0.05$ \\
AIxbr (\%) & Control $(\mathrm{n}=18)$ & $-6.2 \pm 2.82$ & $-7.7 \pm 2.39$ & $-13.8 \pm 17.5$ & $>0.05$ \\
& ALA $(\mathrm{n}=18)$ & $-7.8 \pm 2.17$ & $-12.4 \pm 2.29$ & $-58.0 \pm 18.1$ & $<0.05$ \\
\hline PWV (m/s) & Control $(\mathrm{n}=18)$ & $10.6 \pm 0.36$ & $10.3 \pm 0.36$ & $-2.2 \pm 1.53$ & $>0.05$ \\
& ALA $(\mathrm{n}=18)$ & $10.6 \pm 0.39$ & $9.4 \pm 0.33$ & $-14.3 \pm 2.29$ & $<0.01$ \\
\hline
\end{tabular}

Abbreviations: AIxao - aorta augmentation index; AIxbr - brachial augmentation index; ALA - alpha-lipoic acid; CAN - cardiac autonomic neuropathy; PWV - pulse wave velocity; SEM - standard error of the mean; T2D - type 2 diabetes mellitus. The results are presented as absolute values and as $\%$ change from baseline $(\Delta \%$, mean \pm SEM). 
In conclusion, development of IR leads to increased arterial stiffness parameters independently of BP (Tomiyama et al. 2006).

The pathophysiological link between impaired autonomic function and increased arterial stiffness and whether increased arterial stiffness leads to autonomic dysfunction or whether autonomic dysfunction induces arterial stiffening remains underinvestigated.

Development of both cardiac autonomic dysfunction and increased arterial stiffness is associated with increased activity of pathogenetic pathways, including chronic hyperglycemia, hyperinsulinemia, IR, protein kinase C activation, AGEs formation, endothelial dysfunction, and low-grade inflammation. One explanation is that autonomic dysfunction may increase arterial stiffness, as calcification of the tunica media of the arterial wall is often among persons with CAN (Chorepsima et al. 2017). Another hypothesis could be that impaired cardiac autonomic function may affect arterial wall elasticity by changing large arteries' smooth muscle tone (Liatis et al. 2011; MacFadyen and Lim 2004). Although this explanation is rather difficult to prove in humans, experimental studies have demonstrated that the aorta's elastic properties in rats after sympathectomy were significantly reduced compared with the control group (MacFadyen and Lim 2004). The other explanation could be that arterial stiffness may lead to the CAN development via impairment of baroreceptor function induced by stiffening of the arterial wall (Mattace-Raso et al. 2007).

The search for possible therapeutic options and preventive measures to manage CAN is extremely important. Pathogenetic therapy of CAN includes appropriate physical activity regimen; balanced, healthy diet; IR; intensive glycemic control; treatment of diabetic DLP; antioxidants, such as ALA; vitamins, such as vitamin $B_{1}$; optimization of the cardiac energy metabolism; prevention and treatment of venous thromboembolism; therapy of $\mathrm{OH}$; symptomatic treatment of concomitant diseases and syndromes [HT, CAD, heart failure and arrhythmias)] and others (Hosseini and Abdollahi 2013; Serhiyenko and Serhiyenko 2018; Vinik and Erbas 2013).

Alpha-lipoic acid is considered as a powerful antioxidant with the capacity to raising glutathione (GSH) intracellularly and regenerating other factors such as vitamins E and C (Golbidi et al. 2011). The following ways are thought to clarify the beneficial effects of ALA in reducing the age-associated alterations in GSH: 1) impossible delivery of exogenous GSH to tissues such as the brain and heart and 2) low bioavailability of cysteine delivery agents (e.g., $\mathrm{N}$-acetylcysteine). Despite that, ALA can modulate the age-related alteration in GSH levels as it is easily taken up into neural tissues (Golbidi et al. 2011).

Given the role of OS in CAN, diabetic neuropathy (DN) advancement, antioxidants such as acetylL-carnitine, taurine and ALA have proven to be effective in preventing or delaying the onset of $\mathrm{DN}$, particularly CAN (Boghdadi et al. 2017; Golbidi et al. 2011; Hosseini and Abdollahi 2013; Shay et al. 2009; Vallianou et al. 2009; Ziegler et al. 2011).

Improvements in glucose disposal were observed in patients with T2D receiving ALA either i.v. or p.o. (Shay et al. 2009; Serhiyenko et al. 2018). ALA was also found to increase expression of the insulin receptor substrate 1 (IRS1) protein in the muscle of obese Zucker rats, and it also elicited association of IRS1 with the p85 regulatory subunit of phosphoinositide 3-kinase. In skeletal muscle, ALA is suggested to enroll glucose transporter type 4 (GLUT4) from its storage site in the Golgi to the sarcolemma so that local increase in transporter abundance stimulates the glucose uptake. Evidence from cell culture trials supports the insulin-signaling cascade's involvement in the ALA-stimulated translocation of GLUT1 and GLUT4 (Shay et al. 2009).

Improvement of insulin sensitivity caused by ALA is mediated by 5 adenosine monophosphateactivated protein kinase (AMPK) activation and decrease of triglyceride accumulation in skeletal muscle. The cytoprotective or detrimental effects of ALA on pancreatic beta-cells depend on the concentration of ALA and the underlying pathophysiologic state. It is thought out that at high concentrations ALA is harmful to beta-cells, but at clinically relevant concentrations causes cytoprotective effects (Golbidi et al. 2011). ALA has many actions in the glucose uptake, glycogen synthesis and insulin metabolic pathways with some differences between both isomers. The results of some studies performed in vitro have demonstrated that R-ALA increases the translocation of GLUT4 and GLUT1 to the skeletal muscle cells and the plasmatic membrane of adipocytes kept in a culture milieu (Gomes and Negrato 2014; Wang et al. 2010). ALA has some significant functions in the AMPK expression and activity in the brain and peripheral tissues. AMPK is involved in many intracellular pathways related to cell cycle, stress response, metabolism and aging. ALA could increase the activation of AMPK indirectly by activating the calmodulin-dependent protein kinase. ALA can also modulate the AMPK activity in the brain by metabolic stresses that inhibit ATP produc- 
tion such as OS, glucose deprivation, hypoxia, and ischemia (Gomes and Negrato 2014; Ramamurthy and Ronnet 2012).

The effectiveness of ALA in glucose disposal improvement has been previously shown in animal models (Hosseini and Abdollahi 2013; SoaresMiranda et al. 2012; Tandon et al. 2012) and T2D persons (Hosseini and Abdollahi 2013; SoaresMiranda et al. 2012; Serhiyenko and Serhiyenko 2018). The medication seems to increase insulin sensitivity by increasing the glucose uptake and by modulating the signal transduction.

T2D patients $(\mathrm{n}=57)$ were divided into 2 groups to receive either ALA (300 mg daily) or placebo by systematic randomization and were followed up for 8 weeks. After overnight fasting and 2 hours after breakfast, patients' blood samples were drawn and tested for fasting blood glucose (FBG), serum IRI level, and glutathione peroxidase (GH-Px) activity. The result of the study showed a significant decrease in FBG, HOMA-IR and GH-Px levels in the ALA group. The comparison of differences between FBG and IR at the beginning and at the end of study in the ALA treated group and the placebo group were also significant. This study supports the use of ALA as an antioxidant in the care of diabetic patients (Ansar et al. 2011). Scaramuzza et al. (2015) speculate that ALA might have an antioxidant effect in pediatric diabetes patients by reducing insulin. In T2D persons, an intravenous prescription of 1000 mg of ALA was associated with significant improvement of insulin-stimulated glucose disposal (Jacob et al. 1995). Oral administration of ALA for 4-weeks resulted in insulin sensitivity increasement in T2D patients (Jacob et al. 1999).

Clinically, ALA administration (combined with acetyl-L-carnitine) presented some perspective as an antihypertensive treatment by decreasing systolic BP in high BP patients and subjects with the MetS. In contrast, the administration of ALA (300 mg/day for 4 weeks) to patients with the MetS had no significant effect on BP compared to the placebo group (Pop
Busui et al. 2013; Shay et al. 2009). The combined prescription of ALA and vitamin B complex effectively improved nerve function parallel to symptoms improvement (Boghdadi et al. 2017).

There was a significant reduction after 12 weeks of supplementation in the vitamin B complex plus ALA group using the Michigan Neuropathy Screening Instrument (MNSI) questionnaire and not in the vitamin B complex group. The study demonstrated that 12 out of 16 patients in the group administered with a combination of ALA plus vitamin B complex showed improvement in at least one property measured compared with only 6 out of 16 in the vitamin B complex group. The impact of the combined prescription on the progression of DM regarding IR and lipid profile showed no advantage over vitamin B complex alone (Boghdadi et al. 2017).

The combination of the positive effects of ALA on glucose, IRI content, HOMA-IR, artery stiffness parameters demonstrate the feasibility of its administration in the complex treatment of diabetic CAN. However, further randomized, double-blind, placebo-controlled trials of larger scale and longer duration with better-designed protocol and appropriate selection of study population, doses and duration may provide evidence for the hidden therapeutic capacity of ALA and its potential properties for other diabetic complications such as diabetic CAN.

\section{Acknowledgements}

The research was conducted according to the Declaration of Helsinki (2004) and the Ethics Committee of the Danylo Halitsky Lviv National Medical University approved the study before the initiation (protocol №1 from 01 Jan 2016). The work was performed within the frame of the State task of the Danylo Halitsky National Medical University, Lviv, Ukraine. The authors would like to thank all physicians who approached the patients with type 2 diabetes mellitus and CAN and followed the protocol.

\section{References}

Adeva-Andany MM, Ameneiros-Rodriguez E, Fernandez-Fernandez C, Dominguez-Montero A, Funcasta-Calderon R. Insulin resistance is associated with subclinical vascular disease in humans. World J Diabetes 10, 63-77, 2019.

American Diabetes Association. Standards of medical care in diabetes-2017. Diabetes Care 40, 88-98, 2017.

Ansar H, Mazloom Z, Kazemi F, Hejazi N. Effect of alpha-lipoic acid on blood glucose, insulin resistance, and glutathione peroxidase of type 2 diabetic patients. Saudi Med J 32, 584-588, 2011.

Balcioglu AS, Muderrisoglu H. Diabetes and cardiac autonomic neuropathy: clinical manifestations, cardiovascular consequences, diagnosis and treatment. World J Diabetes 6, 80-89, 2015. 
Boghdadi MA, Afify HE, Sabri N, Makboul K, Elmazar M. Comparative study of vitamin B complex combined with alpha lipoic acid versus vitamin B complex in the treatment of diabetic polyneuropathy in type 2 diabetic patients. Clin Exp Pharmacol 7, 241, 2017.

Chorepsima S, Eleftheriadou I, Tentolouris A, Moyssakis I, Protogerou A, Kokkinos A, Sfikakis PP, Tentolouris N. Pulse wave velocity and cardiac autonomic function in type 2 diabetes mellitus. BMC Endocr Disord 17, 27, 2017.

Colussi G, Catena C, Novello M, Bertin N, Sechi LA. Impact of omega-3 polyunsaturated fatty acids on vascular function and blood pressure: relevance for cardiovascular outcomes. Nutr Metab Cardiovasc Dis 27, 191200, 2017.

Di Flaviani A, Picconi F, Di Stefano P, Giordani I, Malandrucco I, Maggio P, Palazzo P, Sgreccia F, Peraldo C, Farina F, Frajese G, Frontoni S. Impact of glycemic and blood pressure variability on surrogate measures of cardiovascular outcomes in type 2 diabetic patients. Diabetes Care 34, 1605-1609, 2011.

Dimitropoulos G, Tahrani AA, Stevens MJ. Cardiac autonomic neuropathy in patients with diabetes mellitus. World J Diabetes 5, 17-39, 2014.

Emoto M, Nishizawa Y, Kawagishi T, Maekawa K, Hiura Y, Kanda H, Izumotani K, Shoji T, Ishimura E, Inaba M, Okuno Y, Morii H. Stiffness indexes $\beta$ of the common carotid and femoral arteries are associated with insulin resistance in NIDDM. Diabetes Care 21, 1178-1182, 1998.

Ewing DJ, Martyn CN, Young RJ, Clarke BF. The value of cardiovascular autonomic function tests: 10 years experience in diabetes. Diabetes Care 8, 491-498, 1985.

Frontoni S, Di Bartolo P, Avogaro A, Bosi E, Paolisso G, Ceriello A. Glucose variability: An emerging target for the treatment of diabetes mellitus. Diabetes Res Clin Pract, 102, 86-95, 2013.

Golbidi S, Badran M, Laher I. Diabetes and alpha lipoic acid. Front Pharmacol 2, 69, 2011.

Gomes MB, Negrato CA. Alpha-lipoic acid as a pleiotropic compound with potential therapeutic use in diabetes and other chronic diseases. Diabetol Metab Syndr 6, 80, 2014.

Hosseini A, Abdollahi M. Diabetic neuropathy and oxidative stress. Oxid Med Cell Longer 2013, 168039, 2013.

Huikuri HV, Makikallio TH. Heart rate variability in ischemic heart disease. Auton Neurosci 90, 95-101, 2001.

Jacob S, Henriksen EJ, Schiemann AL, Simon I, Clancy DE, Tritschler HJ, Jung WI, Augustin HJ, Dietze GJ. Enhancement of glucose disposal in patients with type 2 diabetes by alpha-lipoic acid. Arzneimittel-Forsch 45, 872-874, 1995.

Jacob S, Ruus P, Hermann R, Ritschler HJT, Maerker E, Renn W, Augustin HJ, Dietze GJ, Rett K. Oral administration of RAC-a-lipoic acid modulates insulin sensitivity in patients with type-2 diabetes mellitus: a placebocontrolled pilot trial. Free Radic Biol Med 27, 309-314, 1999.

Koumaras C, Katsiki N, Athyros VG, Karagiannis A. Metabolic syndrome and arterial stiffness: the past, the present and the future. J Cardiovasc Med (Hagerstown) 14, 687-689, 2013.

La Rovere MT, Pinna GD, Hohnloser SH, Marcus FI, Mortara A, Nohara R, Bigger JT, Camm AJ, Schwartz PJ; ATRAMI Investigators. Autonomic tone and reflexes after myocardial infarction. Baroreflex sensitivity and heart rate variability in the identification of patients at risk for life-threatening arrhythmias: implications for clinical trials. Circulation 103, 2072-2077, 2001.

Lal C, Kaur M, Jaryal AK, Deepak KK, Bhowmik D, Agarwal SK. Reduced baroreflex sensitivity, decreased heart rate variability with increased arterial stiffness in predialysis. Indian J Nephrol 27, 446-451, 2017.

Lee SJ, Jeong SJ, Lee YC, Lee YH, Lee JE, Kim CH, Min KW, Cha BY. Effects of high-dose a-lipoic acid on heart rate variability of type 2 diabetes mellitus patients with cardiac autonomic neuropathy in Korea. Diabetes Metab J 41, 275-283, 2017.

Liatis S, Alexiadou K, Tsiakou A, Makrilakis K, Katsilambros N, Tentolouris N. Cardiac autonomic function correlates with arterial stiffness in the early stage of type 1 diabetes. Exp Diabetes Res 2011, 957901, 2011.

MacFadyen RJ, Lim HS. Emergence of structural arterial stiffness in diabetes and the role of abnormalities of autonomic tone in the sequence of events. J Hum Hypertens 18, 755-756, 2004.

Manrique C, Lastra G, Sowers JR. New insights into insulin action and resistance in the vasculature. Ann N Y Acad Sci 1311, 138-150, 2014.

Mansour AS, Yannoutsos A, Majahalme N, Agnoletti D, Safar ME, Ouerdane S, Blacher J. Aortic stiffness and cardiovascular risk in type 2 diabetes. J Hypertens 31, 1584-1592, 2013.

Markus MRP, Rospleszcz S, Ittermann T, Baumeister SE, Schipf S, Siewert-Markus U, Lorbeer R, Storz C, Ptushkina V, Peters A, Meisinger C, Bamberg F, Nauck M, Bahls M, Volzke H, Burkhard Felix S, Bulow R, Rathmann W, Dorr M. Glucose and insulin levels are associated with arterial stiffness and concentric remodeling of the heart. Cardiovasc Diabetol 18, 145, 2019. 
Maser RE, Mitchell BD, Vinik AI, Freeman R. The association between cardiovascular autonomic neuropathy and mortality in individuals with diabetes a meta-analysis. Diabetes Care 26, 1895-1901, 2003.

Mattace-Raso FU, van den Meiracker AH, Bos WJ, van der Cammen TJ, Westerholf BE, Elias-Smale S, Reneman RS, Hoeks AP, Hofman A, Witteman JC. Arterial stiffness, cardiovagal baroreflex sensitivity and postural blood pressure changes in older adults: the Rotterdam Study. J Hypertens 25, 1421-1426, 2007.

Matthews DR, Hosker JP, Rudenski AS, Naylor BA, Treacher DF, Turner RC. Homeostasis model assessment: insulin resistance and beta-cell function from fasting plasma glucose and insulin concentrations in man. Diabetologia 28, 412-419, 1985.

Morioka T, Mori K, Emoto M. Is stiffness parameter $\beta$ useful for the evaluation of atherosclerosis? Its clinical implications, limitations, and future perspectives. J Atheroscler Thromb 28, 435-453, 2021.

Olsen MH, Fossum E, Hjerkinn E, Wachtell K, Hoieggen A, Nesbitt SD, Andersen UB, Phillips RA, Gaboury CL, Ibsen H, Kjeldsen SE, Julius S. Relative influence of insulin resistancevs blood pressure on vascular changes in longstanding hypertension. ICARUS, a LIFE substudy. Insulin Carotids US Scandinavia. J Hypertens 18, 75-81, 2000.

Pop Busui R, Stevens MJ, Raffel DM, White EA, Mehta M, Plunkett CD, Brown MB, Feldman EL. Effects of triple antioxidant therapy on measures of cardiovascular autonomic neuropathy and on myocardial blood flow in type 1 diabetes: a randomized controlled trial. Diabetologia 56, 1835-1844, 2013.

Pop-Busui R, Boulton AJM, Feldman EL, Bril V, Freeman R, Malik RA, Sosenko JM, Ziegler D. Diabetic neuropathy: a position statement by the American Diabetes Association. Diabetes Care 40, 136-154, 2017.

Ramamurthy S, Ronnet G. AMP-activated protein kinase (AMPK) and energy sensing in the brain. Exp Neurobiol 21, 52-60, 2012.

Scaramuzza A, Giani E, Redaelli F, Ungheri S, Macedoni M, Giudici V, Bosetti A, Ferrari M, Zuccotti GV. Alphalipoic acid and antioxidant diet help to improve endothelial dysfunction in adolescents with type 1 diabetes: A Pilot Trial. J Diabetes Res 2015, 474561, 2015.

Sengstock DM, Vaitkevicius PV, Supiano MA. Arterial stiffness is related to insulin resistance in nondiabetic hypertensive older adults. J Clin Endocrinol Metab 90, 2823-2827, 2005.

Serhiyenko VA, Serhiyenko AA. Diabetic cardiac autonomic neuropathy: Do we have any treatment perspectives? World J Diabetes 6, 245-258, 2015.

Serhiyenko VA, Serhiyenko AA. Cardiac autonomic neuropathy: Risk factors, diagnosis and treatment. World J Diabetes 9, 1-24, 2018.

Serhiyenko V, Serhiyenko L, Krasnyi M, Serhiyenko A. Alpha-lipoic acid: therapeutic potential in diabetic neuropathies. Curre Res Diabetes Obes J 7, 555713, 2018.

Sessa F, Anna V, Messina G, Cibelli G, Monda V, Marsala G, Ruberto M, Biondi A, Cascio O, Bertozzi G, Pisanelli D, Maglietta F, Messina A, Mollica MP, Salerno M. Heart rate variability as predictive factor for sudden cardiac death. Aging (Albany NY), 10, 166-177, 2018.

Shay KP, Moreau RF, Smith EJ, Smith AR, Hagen TM. Alpha-lipoic acid as a dietary supplement: molecular mechanisms and therapeutic potential. Biochim Biophys Acta 1790, 1149-1160, 2009.

Sleight P, La Rovere MT, Mortara A, Pinna G, Maestri R, Leuzzi S, Bianchini B, Tavazzi L, Bernardi L. Physiology and pathophysiology of heart rate and blood pressure variability in humans: is power spectral analysis largely an index of baroreflex gain? Clin Sci 99, 103-109, 1995.

Soares-Miranda L, Sandercock G, Vale S, Santos R, Abreu S, Moreira C, Mota J. Metabolic syndrome, physical activity and cardiac autonomic function. Diabetes Metab Res Rev 28, 363-369, 2012.

Spallone V, Ziegler D, Freeman R, Bernardi L, Frontoni S, Pop-Busui R, Stevens M, Kempler P, Hilsted J, Tesfaye S, Low P, Valensi P; Toronto Consensus Panel on Diabetic Neuropathy. Cardiovascular autonomic neuropathy in diabetes: clinical impact, assessment, diagnosis, and management. Diabetes Metab Res Rev 27, 639-653, 2011.

Stehouwer CD, Henry RM, Ferreira I. Arterial stiffness in diabetes and the metabolic syndrome: a pathway to cardiovascular disease. Diabetologia 51, 527-539, 2008.

Tandon N, Ali MK, Narayan KM. Pharmacologic prevention of microvascular and macrovascular complications in diabetes mellitus: implications of the results of recent clinical trials in type 2 diabetes. Am J Cardiovasc Drugs 12, 7-22, 2012.

TensioClinicTensioMed ${ }^{\mathrm{TM}}$ Arteriograph and TensioMed ${ }^{\mathrm{TM}}$ program. Available from: http//www.arteriograph.nl/? act=download\&fid=173.

Tesfaye S, Boulton AJM, Dyck PJ, Freeman R, Horowitz M, Kempler P, Lauria G, Malik RA, Spallone V, Vinik A, Bernardi L, Valensi P; Toronto Diabetic Neuropathy Expert Group. Diabetic neuropathies: update on definitions, diagnostic criteria, estimation of severity, and treatments. Diabetes Care 33, 2285-2293, 2010. 
Tomiyama H, Hashimoto H, Hirayama Y, Yambe M, Yamada J, Koji Y, Shiina K, Yamamoto Y, Yamashina A. Synergistic acceleration of arterial stiffening in the presence of raised blood pressure and raised plasma glucose. Hypertension 47, 180-188, 2006.

Townsend RR, Wilkinson IB, Schiffrin EL, Avolio AP, Chirinos JA, Cockcroff JR, Heffernan KS, Lakatta EG, McEniery CM, Mitchell GF, Najjar SS, Nichols WW, Urbina EM, Weber T; American Heart Association Council on Hypertension. Recommendations for improving and standardizing vascular research on arterial stiffness: a scientific statement from the American Heart Association. Hypertension 66, 698-722, 2015.

Vallianou N, Evangelopoulos A, Koutalas P. Alpha-lipoic acid and diabetic neuropathy. Rev Diabet Stud 6, 230-236, 2009.

van Dijk RA, Bakker SJ, Scheffer PG, Heine RJ, Stehouwer CD. Associations of metabolic variables with arterial stiffness in type 2 diabetes mellitus: focus on insulin sensitivity and postprandial triglyceridaemia. Eur J Clin Invest 33, 307-315, 2003.

Verrotti A, Prezioso G, Scattoni R, Chiarelli F. Autonomic neuropathy in diabetes mellitus. Front Endocrinol (Lausanne) 5, 205, 2014.

Vinik AI, Erbas T. Diabetic autonomic neuropathy. Handb Clin Neurol 17, 279-294, 2013.

Vinik AI, Erbas T, Casellini CM. Diabetic cardiac autonomic neuropathy, inflammation and cardiovascular disease. J Diabetes Investig 4, 4-18, 2013.

Vinik AI, Casellini C, Parson HK, Colberg SR, Nevoret ML. Cardiac autonomic neuropathy in diabetes: A predictor of cardiometabolic events. Front Neurosci 12, 591, 2018.

Wang Y, Li X, Guo Y, Chan L, Guan X. Alpha-lipoic acid increases energy expenditure by enhancing adenosine monophosphate-activated protein kinase-peroxisome proliferator-activated receptor-gamma coactivator-1 alpha signaling in the skeletal muscle of aged mice. Metabolism 59, 967-976, 2010.

Yki-Jarvinen H, Westerbacka J. Insulin resistance, arterial stiffness and wave reflection. Adv Cardiol 44, 252260, 2007.

Ziegler D, Schatz H, Conrad F, Gries FA, Ulrich H, Reichel G. Effects of treatment with the antioxidant alphalipoic acid on cardiac autonomic neuropathy in NIDDM patients. A 4-month randomized controlled multicenter trial (DEKAN Study). Deutsche Kardiale Autonome Neuropathie. Diabetes Care 20, 369373, 1997.

Ziegler D, Low PA, Litchy WJ, Boulton AJ, Vinik AI, Freeman R, Samigullin R, Tritschler H, Munzel U, Maus J, Schutte K, Dyck PJ. Efficacy and safety of antioxidant treatment with a-lipoic acid over 4 years in diabetic polyneuropathy: the NATHAN 1 trial. Diabetes Care 34, 2054-2060, 2011.

Ziegler D, Keller J, Maier C, Pannek J; German Diabetes Association. Diabetic neuropathy. Exp Clin Endocrinol Diabetes 122, 406-415, 2014. 